\title{
If-conditionals in Authentic Corpus-based English
}

\author{
Supakorn Phoocharoensil ${ }^{1}$ \\ ${ }^{1}$ Language Institute of Thammasat University, Bangkok, Thailand \\ Correspondence: Supakorn Phoocharoensil, Language Institute of Thammasat University, 2 Phrachan Road \\ Phranakorn Bangkok 10200, Thailand. Tel: 66-2-6133-1013. E-mail: yhee143@gmail.com
}

Received: April 30, 2014 Accepted: June 17, 2014 Online Published: August 15, 2014

doi:10.5539/res.v6n3p62 URL: http://dx.doi.org/10.5539/res.v6n3p62

\begin{abstract}
This research paper focuses on an investigation of if-conditional structures in naturally-occurring American English. The corpus-based analysis has revealed several alternative grammatical constructions, all of which occurred with higher frequency than the three traditional main types, which actually accounted for less than half of the entire if-conditional occurrences in the corpus, included in most ELT textbooks, lending support to previous studies (e.g. Gabrielatos, 2006, 2013). The study, furthermore, also discovered a current trend in native English speakers' grammar, i.e. the preponderance of was over were in the second conditional, despite the fact that pedantic, prescriptive grammarians would disallow was in this if-clause type, which accords with Novogradec (2009). It is also very interesting to find dominant features of spoken English in connection with if-conditionals, namely gonna and other contractions, false starts, ellipses, and fillers. The last section pertains to pedagogical implications, offering some useful advice for teachers to incorporate authentic corpus-informed if-patterns into their instruction.
\end{abstract}

Keywords: corpus linguistics, English if-conditionals, corpus-based study, corpora, spoken English

\section{Introduction}

Traditional grammar references as well as coursebooks apparently present to English learners three classic types of conditionals, commonly known as the first, second, and third conditionals. Only a few advanced resources sometimes mention other possibilities, i.e. alternative if-conditional patterns that do not conform to this prevailing typology. It may strike English learners, especially those with high exposure to English, as peculiar that a large number of conditionals in real English, e.g. films, news reports, everyday conversation, fiction, etc. do differ from what they have been mainly taught in EFL/ESL classrooms. In actuality, the conditional structures that occur in native speakers' language turn out to be far more different from the aforementioned classic paradigm. Learners of English could become easily confused over the possible constructions of if-conditionals and the meaning represented by each unusual, atypical combination.

The present study was aimed at investigating the if-conditionals existing in authentic spoken American English, i.e. the data drawn from a corpus of American English (COCA), compared with those available in standard English language teaching (ELT) coursebooks widely used in Thailand. Not only did the researcher concentrate on finding possible if-conditional structures, aside from the three principal types, but also the use of was in the second conditional, which is banned according to the so-called prescriptive grammar, was under examination. In addition, outstanding spoken features of if-conditionals are outlined and comprehensively discussed in the subsequent subsection, or 6.2.2. The article ends with some implications for English teaching and the author's suggestions for if-conditional lesson preparation.

\section{Literature Review}

\subsection{English If-conditionals: The Traditional Typology}

If-conditionals in English are typically composed of two parts: a conditional clause and a main clause. The conditional clause or if-clause, also known as a protasis, usually begins with the subordinating conjunction if, while the main clause, sometimes referred to as an apodosis, deals with the situation dependent on the condition represented in the if-clause (Werth, 1997).

As introduced in general English grammar references, there seem to exist three basic types of English if-conditionals: the first conditional, the second conditional, and the third conditional. Ferguson (2001, p. 64) 
exemplifies these three conditional constructions as follows:

(1) First conditional: present + will + verb in the base form (if it rains, we'll go home.)

(2) Second conditional: past + would + verb in the base form (if it rained, we would go home.)

(3) Third conditional: past perfect + would have + V.3 (if it had rained, we would have gone home.)

To be precise, the first conditional conventionally requires the present simple tense in the if-clause and the use of the modal will or its contraction' $l l$ in the main clause, as in (4) and (5). This conditional type is used to describe possible future events or situations and their results (Foley \& Hall, 2003). In other words, a likely result in the future is predicted if the condition is fulfilled (Carter \& McCarthy, 2006)

(4) If he moves to Manchester, he will have to sell his house in Bristol.

(Carter \& McCarthy, 2006, p. 748)

(5) If we play tennis, I'll win.

(Swan, 2005, p. 233)

Other modals with future reference, in addition to will, e.g. may, can, or should, are also possible in the main clause of the first conditional, as can be seen in (6)-(8).

(6) If your documents are in order you may leave at once.

(adapted from Thomson \& Martinet, 1986, p. 197)

(7) If it stops snowing we can go out.

(Thomson \& Martinet, 1986, p. 197)

(8) If the Spanish team continues to do so well, they should win the World Cup.

(Foley \& Hall, 2003, p. 121)

The second conditional consists of if + the past simple tense + would + verb in the base form, as shown in (9). The main clause, it is worth noting that, also allows other modals with future-in-the-past reference, e.g. could or might. In terms of semantics, this type of conditional possibly expresses two main meanings (Foley \& Hall, 2003): a.) it is used to describe an improbable future event or situation, as in (10), or b.) it discusses a hypothetical event or situation in the present time, as in (11).

(9) If I knew her name, I would tell you.

(Swan, 2005, p. 235)

(10) If Mike rang the travel agent tomorrow, he might get a cancellation.

(Foley \& Hall, 2003, p. 122)

(11) If the police were confident of their case against Sykes, surely they wouldn't hesitate to take him into custody?

(Foley \& Hall, 2003, p. 122)

In (10), the speaker thinks it is unlikely that Mike will call the travel agent, whereas (11) implies the police' lack of confidence in their case.

One of the most outstanding rules governing the second conditional lies in the use of be. That is, were, as in (12) and (13), seems to be more common than was in both formal and informal styles. In particular, the subjunctive were is often considered more preferable or even more correct for all persons, especially in American English (Swan, 2005, p. 235).

(12) If I were rich, I would spend all my time travelling.

(Swan, 2005, p. 235)

(13) If my nose were a little shorter I'd be quite pretty.

(Swan, 2005, p. 235)

The final type of English conditional, i.e., the third conditional, is the most complex in syntactic structure, comprising if + past perfect + would have + past participle, as in (14) (Foley \& Hall, 2003). Similar to the second conditional, the third type also permits other modals with future-in-the-past reference, e.g. could and might, in the main clause, as in (15) and (16) respectively. 
(14) If we had paid our cleaner more, she wouldn't have left us.

(Foley \& Hall, 2003, p. 123)

(15) If the spy had intercepted the message, he could have averted the crisis.

(Foley \& Hall, 2003, p. 123)

(16) It might have been easier to break the news if I had known her a bit better.

(Foley \& Hall, 2003, p. 123)

In terms of meaning, the third conditional describes the speaker's or writer's attitude toward an imaginary situation in the past. According to Carter and McCarthy (2006, p. 748), “...the speaker or writer is talking about a past event which did not happen, and therefore things are different from how they might have been". Put simply, the past situation is contrary to known facts (Foley \& Hall, 2003).

Apart from the three classic if-conditionals, there exist in certain grammar textbooks some special types, one of which is referred to as the zero conditional, which contains the present simple tense in both the if-clause and the main clause. The zero conditional is used to discuss events or situations that are general truths or facts, i.e., those that are possible at any time (Foley \& Hall, 2003), as in (17).

(17) If you don't look after tomato plants, they die very quickly.

(Foley \& Hall, 2003, p. 123)

The three conditional types mentioned above appear to be taken as standard or common in most EFL textbooks despite the fact that combinations of different verb tenses, apart from those outlined in the traditional paradigm, have actually turned out to be prevalent in native English speakers' spoken and written language. The possibilities of mixed conditionals, which seem to be rarely touched upon in several EFL textbooks, should be more focused on due to their high frequency in real language use, as clearly shown through the corpus-based studies to be discussed in 2.2 .

\subsection{If-conditional Use in Corpus-based Authentic English}

Even though the three main types of if-conditionals, as illustrated in the previous section, are apparently highlighted in a number of English textbooks, corpus-based research provide undeniable evidence of quite a few occurrences of mixed conditional structures. Farr and McCarthy (2002) made a comparison between the 60,000-word POTTI (Post-Observation-Teacher-Training Interactions) corpus with CANCODE (Cambridge and Nottingham Corpus of Discourse in English), focusing on three hypothetical items, namely if, maybe, and perhaps. The study demonstrated that if occurred more frequently than maybe and perhaps respectively in a 2.6-million-word sub-corpus of everyday socializing interactions from CANCODE and the spoken academic portion of CANCODE of around 340,000 words. While the occurrences of if in POTTI also outnumbered the other two items, more tokens of perhaps than maybe were witnessed.

More interestingly, Farr and McCarthy indicated that the three if-conditional types regarded as classic in most textbooks did not dominate the POTTI corpus. That is to say, there was a wide range of if-patterns reflecting highly flexible structures, which can be adapted to conditions of use. The pattern occurring with the highest frequency, of all the occurrences of 160 if-conditionals, turned out to be the zero or real conditional ( 55 tokens), followed by Type 1 (28 tokens). A variety of if-patterns not falling into any of the three conventional types emerged in the corpus data, and three alternative if-structures appeared to be even more frequent than Type 3 conditionals. On the whole, the three classic types of if-conditionals accounted for fewer than half of the entire uses in the corpus. Some examples of alternative if-patterns from POTTI are given in (18)-(19) (Farr \& McCarthy, 2002; as cited in O'Keeffe, McCarthy, \& Carter, 2007, p. 129).

(18) If you're teaching that class don't feel obliged to explain everything to her.

(19) ....if you had to be putting on a performance then I get really on edge,....

That if-conditionals are of various patterns, as demonstrated by Farr and McCarthy (2002), bears out Ferguson (2000), whose focus was on if-conditionals in medical discourse. Ferguson, more precisely, examined if-patterns in three genres, viz. research articles, journal editorials, and doctor-patient consultations. The corpus-informed data indicated that the three classic if-conditional types were not used very frequently. "...only $18 \%$ of conditional sentences in the whole data set conform to the first, second, and third conditional paradigm of many EFL pedagogic grammar" (Ferguson, 2000, pp. 69-70). Put differently, the traditional typology does not represent the actual uses of if-conditionals by native English speakers. Even the zero conditional was found to be used with more frequency (21\%) than the total three main types (18\%). According to Ferguson (2000), one of the 
very common constructions (28\%) concerns the pattern consisting of the present tense + modal verb pattern (in addition to the use of will). Despite Ferguson's classification of such an if-construction comprising such modals as might, may, can, into an alternative, unconventional type independent of the classic typology, it is worth noticing here that some grammarians (e.g. Foley \& Hall, 2003) view this pattern as a subcategory of Type I. Were these modals to be included in the Type I conditional, 39\% of the first conditionals would result, which would be considered the most frequent one.

What is more interesting, nevertheless, lies not in the subcategories of the three typical if-patterns but in other constructions that deviate from the norm. For example, in journal articles, which tend to report on research methods and results using past tenses, the salience of past simple + past simple, as in (20) and (21) was noticeable.

(20) Patients were eligible for this trial if they satisfied the criteria for high-risk disease.

(Ferguson, 2000, p. 71)

(21) Each drug was supervised and the full dosing was repeated if vomiting occurred within one hour.

(Ferguson, 2000, p. 71)

Another distinctive use of if-conditionals found in doctor-patient consultations pertains to polite directives used to elicit patients' symptoms, as in (22), because the if-clause "...seems...to make the proposed action on the part of the addressee contingent on the willingness of that addressee, in this case the patient" (Ferguson, 2000, p. 77). On some occasions, the apodosis or main clause are omitted, as in (23). Furthermore, the use of pragmatic if-conditionals is also interesting in that an if-clause and a main clause are sometimes distributed across different speaker turns, as in (24).

(22) If I'm sort of thinking about something else while I'm eating, then it ... doesn't work properly.

(Ferguson, 2000, p. 77)

(23) If you ask at the desk.

(Ferguson, 2000, p. 78)

(24) Doctor: And if it was to happen now.

Patient: I'd sort of have to look up, like that.

(Ferguson, 2000, p. 77)

Novogradec (2009) reported on useful findings with respect to the frequency and the occurrences of the hypothetical if-conditionals the if-clause of which begins with if I was and if I were. The researcher seemed to predict and presuppose the common use of was in native speaker corpora, in spite of the fact that some traditional, prescriptive grammarians prefer were in the second conditional. The data were drawn from three main sub-corpora, namely senate speeches, newspaper articles, and TV scripts of the series Friends, supplemented by another sub-corpus from the British National Corpus (BNC) of spoken and written language.

The TV series data, representing spoken English, showed the preponderance of was over were, as in (25) and (26). Such findings clearly violate the prescriptive rule that only were is allowed in Type II conditionals. According to Novogradec, the idea presented in grammar textbooks that were rather than was belongs to standard English has probably been doubted or even disproved since in reality was evidently prevailed.

(25) If I was in this for the money, I'd be a millionaire.

(Novogradec, 2009, p. 72)

(26) I'm sorry if I was a little weird after the last time we went out.

(Novogradec, 2009, p. 73)

Not only the data from the aforementioned corpora, but also the BNC data confirmed the actual common occurrences of was in the second conditional. Novogradec encouraged textbook writers to consider incorporating corpus evidence of if-conditionals as students should be presented with information of authentic English, as opposed to invented examples from textbooks alone.

There have also been studies that investigated ELT coursebooks with emphasis on if-conditionals. Of all these research studies, Gabrielatos has been continually making a great effort to compare and contrast in information present in textbooks and corpora. As shown in Gabrielatos (2006), the if-conditional information available in elevenELT coursebooks does not cover all the salient if-patterns of authentic English. For instance, rarely are 
mixed types mentioned; the zero and first conditionals are not clearly differentiated. In addition, modality in the conditionals is presented in a limited, potentially misleading fashion. In other words, main clauses expressing other modal senses, e.g. obligation, are often ignored in ELT coursebooks.

Gabrielatos (2013) compared L1 if-conditional use with learner use as well as pedagogical information from textbooks. It was expected that the conditionals produced by learners might be indicative of certain problems, whereas those of L1 speakers should provide insights into the level of representativeness of textbook information. Moreover, it was estimated that the information given in coursebooks may influence learners' use of if-conditionals. Gabrielatos collected learner uses of conditionals from ICLE, a corpus of learner writings, all of which are argumentative essays, at upper-intermediate and advanced levels. As regards the L1 if-patterns, the data were derived from the BNC with focus on instances from academic texts, essays, and editorials.

The ICLE corpus-based data revealed more if-conditionals than did the BNC ones, probably due to the fact that conditionals are prevalent in most ELT textbooks and should be familiar to learners. Additionally, they may feel they are supposed to regularly use conditionals in their essays. It is also noteworthy that ELT coursebooks predominantly concentrate on if-conditionals in expressing conditions. Therefore, it is very likely that learners will underuse other conditional structures without the conjunction if.

Another important discovered fact from ICLE concerns the learners' production of if-conditionals other than what is available in the ELT materials. Simply put, they used if-patterns that are beyond the information presented in coursebooks. As Gabrielatos remarked, "...the overall use of if-conditionals by the ICLE students is not strongly influenced by the shortcomings of the ELT typology and related pedagogical information" (p. 11). This may be attributed to the students' exposure to English outside the classroom or application of certain learning strategies.

\section{Research Question}

What are the occurrences of if-conditionals found in Corpus of Contemporary American English (COCA)?

\section{Hypothesis}

The if-conditionals existing in authentic American English, as shown in COCA data, are of various types, many of which are often not present in ELT coursebooks.

\section{Research Method}

\subsection{Data Sources}

The language data in the present study were drawn from two main sources. The first group of data was derived from the sections of conditionals in five intermediate and upper-intermediate ELT coursebooks, i.e. Face2face, Headway, New Opportunities, New English File, and Passages widely used in Thailand, whereas the other dataset is concerned with real uses of if-conditionals from corpus-informed data.

The corpus consulted in the current research study was Corpus of Contemporary American English (COCA), which is claimed to be the largest corpus of American English, created by Mark Davies from Brigham Young University. With over 450 million words of texts, COCA obtains linguistic data from different genres, namely spoken, fiction, popular magazines, newspapers, and academic texts (Lindquist, 2006). It, moreover, includes 20 million words each year from 1990-2012 and the corpus is also updated regularly. Researchers, for this reason, can benefit from COCA when searching for current as well as ongoing changes in English.

\subsection{Data Collection Procedure}

Basically, the principal source of data was COCA, where 400 concordance lines of if were randomly searched for. Then those lines were sorted out to make sure only if-conditionals were made ready for the subsequent analysis. In other words, the conjunction if with other functions, e.g. a marker of an indirect question, as in I asked if she had any letters for me (adapted from Swan, 2005, p. 671), would be first excluded. There were eventually 164 true if-conditionals left to be analyzed. Apart from the corpus-based data, the sections on if-conditionals from the five aforementioned coursebooks were taken into consideration for a further comparison with the corpus data.

\subsection{Data Analysis}

The study was aimed at comparing and contrasting the information on English conditionals provided by the coursebooks and that from naturally occurring data, in the expectation of exploring and discovering if-conditional constructions that are not existent in ELT coursebooks, i.e., those that differ from what belongs to the classic typology. The entire number of corpus-based if-patterns were counted and classified before being tabulated according to frequency. 


\section{Results and Discussion}

Table 1. Distribution of if-conditionals in COCA

\begin{tabular}{|c|c|c|}
\hline Type of if-conditional & frequency & $\%$ \\
\hline Type I & & \\
\hline - With will in the main clause & 20 & \\
\hline & 43 & 26.22 \\
\hline - With other modals, e.g. can, may, should & 23 & \\
\hline Zero conditional & 34 & 20.73 \\
\hline If + present simple + imperative & 22 & 13.14 \\
\hline Type II & & \\
\hline - With would in the main clause & 14 & \\
\hline - With other modals, e.g. could, might & -20 & 12.20 \\
\hline & 6 & \\
\hline If + present simple $+\mathrm{S}+$ be (present) + going to $+V_{\text {infinitive }}$ & 8 & 4.88 \\
\hline If + past simple $+S+$ would have $\quad \mathrm{V} .3$ & 4 & 2.44 \\
\hline If + present simple + present progressive & 4 & 2.44 \\
\hline Type III & 3 & 1.83 \\
\hline If + present simple $+S+$ would $/$ could $+V_{\text {:infinitive }}$ & 3 & 1.83 \\
\hline If $+\mathrm{S}+$ would/could $+\mathrm{V}_{\text {:infinitive }}, \mathrm{S}+$ would $+\mathrm{V}_{\text {:infinitive }}$ & 3 & 1.83 \\
\hline If $+\mathrm{S}+$ be (present) + going to $+\mathrm{V}_{\text {.infinitive }}+$ present simple & 3 & 1.83 \\
\hline If + present progressive + present progressive & 3 & 1.83 \\
\hline If + present perfect + present simple & 2 & 1.22 \\
\hline If $+\mathrm{S}+$ can $+\mathrm{V}_{\text {:infinitive }}, \mathrm{S}+$ can $+\mathrm{V}_{\text {-infinitive }}$ & 2 & 1.22 \\
\hline If + present progressive $+\mathrm{S}+$ can $+\mathrm{V}_{\text {-infinitive }}$ & 2 & 1.22 \\
\hline If $+\mathrm{S}+$ could $+\mathrm{V}_{\text {:infinitive }}+$ present simple & 1 & 0.61 \\
\hline If + past perfect $+S+$ might $+V_{\text {infinitive }}$ & 1 & 0.61 \\
\hline If $+\mathrm{S}+$ will $+\mathrm{V}_{\text {-infinitive }}+\mathrm{S}+$ was going to $+\mathrm{V}_{\text {-infinitive }}$ & 1 & 0.61 \\
\hline If $+\mathrm{S}+$ would have $\quad \mathrm{V} .3, \mathrm{~S}+$ would $+V$. .infinitive & 1 & 0.61 \\
\hline If $+S+$ can $+V_{\text {:infinitive }}, S+$ will $+V_{\text {:infinitive }}$ & 1 & 0.61 \\
\hline If + past simple + present simple & 1 & 0.61 \\
\hline $\begin{array}{l}\text { If }+\mathrm{S}+\text { be (present) }+ \text { going to }+\mathrm{V}_{\text {infinitive }}, \mathrm{S}+\text { be (present) }+ \text { going to }+ \\
\mathrm{V}_{\text {-infinitive }}\end{array}$ & 1 & 0.61 \\
\hline If + past simple + past simple & 1 & 0.61 \\
\hline TOTAL & 164 & 100 \\
\hline
\end{tabular}

\subsection{Findings}

According to Table 1, if-conditionals in American English, as illustrated by COCA, took a variety of verb-tense patterns. In addition to the three conventional types, there were up to 20 alternative types, including the zero conditional. It is clearly seen that the three classic if-conditional construction accounted for less than half (66 tokens $/ 40.24 \%$ ) of the total occurrences (164 tokens). The most frequent if-structure was the first conditional (43 tokens/26.22\%). It should also be noted here that $12.20 \%$ (20 tokens) of Type I contained the modal will in the main clauses, as in (27), whereas $14.02 \%$ (23 tokens) involved uses of other modals, e.g. can, may, should, and have to, as in (28), (29), (30), and (31) respectively. 
(27) If you don't leave this case alone, I will ruin you politically, publicly.

(28) If this is what fashionable, I can do it better than the other people.

(29) hundreds of thousands of them may die if an effective vaccine is not developed.

(30) If you don't know the procedure, you should be represented.

(31) If we don't make, I have to make a decision by Friday...

Second to Type I in frequency was the zero conditional (34 tokens/20.73\%), as shown in (32), followed by the extraordinary construction If + present simple + imperative, in (33). The corpus data indicated that the functions of the main clauses are affirmative commands, as in (34), and negative commands, as in (35)

(32) If it smells, the dog takes it.

(33) I'm ready to play if you are, Alan.

(34) If you don't want our child, give him to me to raise.

(35) If you love Natalie, do not tell a soul that Natalie's pregnant.

The if-pattern that was ranked fourth in frequency was Type II (20 tokens/12.20\%). Like Type I, Type II conditionals, as demonstrated by the data, were of two subcategories, namely those with would (14 tokens/ $8.54 \%$ ), as in (36), and those made up of other modals, e.g. could, might (6 tokens/ 3.66\%) in the main clauses, as can be seen in (37)-(38).

(36) If he apologized I would forget about it.

(37) He could go to jail if he lied.

(38) ...what might happen if terrorists attacked an American city with deadly anthrax,...

The construction If + present simple $+S+$ be (present) + going to $+V_{\text {.infinitive, }}$ as in (39), was found to be the fifth in frequency ( 8 tokens/ $4.88 \%$ ), followed by the two alternative structures, i.e., If + past simple $+S+$ would have V.3, as in (40), and If + present simple + present progressive, as in (41), both of which occurred equally (4 tokens/ $2.44 \%$ ).

(39) If you leave Sinat-Sinatra off, you're going to be totally embarrassed.

(40) If it was meant for you to die today, you wouldn't have found this.

(41) If this war continues, I'm taking you to Canada!

To the researcher's surprise, the third conditional, as in (42), which seems to be clearly highlighted in all the consulted ELT coursebooks, occurred only $1.83 \%$ ( 3 tokens). To be more specific, only the modal would, as opposed to other possible modals, e.g. could or should, was found in the data. Equally ranked alongside Type III were another four unconventional if-patterns, namely, If + present simple $+S+$ would/could $V_{\text {.infinitive }}$, as in (43) and (44), If $+S+$ would/could $+V_{\text {.infinitive, }} S+$ would $+V_{\text {infinitive, }}$ as in (45) and (46), If $+S+$ be (present) + going to $+V_{\text {infinitive }}+$ present simple, as in (47), and If + present progressive + present progressive, as in (48).

(42) If that gun had been in my house, there wouldn't have been a tragedy.

(43) I think everybody would understand if you're on trial.

(44) He could lose if there's a low voter turnout.

(45) ...they would find the money to pay if they could be guaranteed no further litigation.

(46) If God would take my sight away now again, I'd be happy.

(47) If you're not going to use your army, I use it.

(48) ....if they aren't getting that, somehow they're missing out.

The next group of if-conditionals the verb-tense patterns of which are different from the classic paradigm occurred two times $(1.22 \%)$. These conditional structures were $I f+$ present perfect + present simple, as in (49),

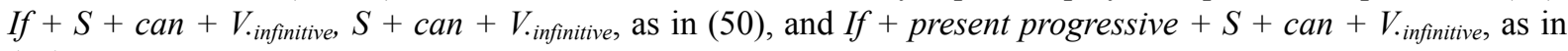
(51).

(49) If you've got nothing to hide, what are you afraid of?

(50) If he can do it, I can do it.

(51) You can hustle if you're winning or losing. 
The least frequent if-conditionals $(0.61 \%)$ found in this corpus concern eight syntactic constructions, namely If + $S+$ could $+V_{\text {.infinitive }}+$ present simple, as in (52), If + past perfect $+S+$ might $+V_{\text {infinitive, }}$ as in (53), If $+S+$ will $+V_{\text {infinitive }}+S+$ was going to $+V_{\text {.infinitive }}$ as in (54), If $+S+$ would have $+V \cdot 3, S+$ would $+V_{\text {.infinitive, }}$ as in (55), If $+S+$ can $+V_{\text {infinitive, }} S+$ will $+V_{\text {infinitive, }}$ as in (56), If + past simple + present simple, as in (57), If $+S+$ be $($ present $)+$ going to $+V_{\text {.infinitive, }} S+$ be (present) + going to $+V_{\text {infinitive }}$ and $I f+$ past simple + past simple, as in (58) and (59) respectively.

(52) ...there is a third of the vote out there that is easily his to get if he could pull that vote.

(53) I think if he'd had a chance to be Treasury secretary or something, he might stay.

(54) If he won't tell the truth, I was going to tell the truth.

(55) If you would have been, the three of you would be dead now...

(56) If-if we can just sit tight here, someone will come!

(57) If an 8.3 earthquake in 1906 didn't stop my grandparents, a 6.6 isn 't.

(58) If we're going to release this, it's going to smear the whole...

(59) If it happened, it was their fault.

\subsection{If-conditionals in COCA}

\subsubsection{Authentic Uses of If-conditionals}

It is evident from the corpus-based data derived from COCA, a representative of real use of English, that if-conditionals actually occur in a far greater number of constructions than what is included in the English textbooks prevalent in Thai schools, as well as in other EFL countries. The results support the hypothesis, which claimed that the if-conditionals in authentic American English, as indicated by COCA data, have a variety of patterns, many of which are absent in many ELT coursebooks. To illustrate, all the textbooks consulted clearly stress the classic typology, i.e., the three principal if-clause types. Only some introduce the zero-conditional with a few instances and very short explanation on its usage. Barely are mixed-types existent in any of them, probably because the authors may believe the students could be overwhelmed by excessive amount of grammatical information. However, even the coursebooks which are aimed at upper-intermediate readers disappointingly abstain from introducing such mixed patterns, which prove commonplace in native speaker language.

\section{Modal Uses in If-clauses}

As indicated by the corpus data from COCA, plenty of if-conditional structures violate the classic typology in such a way that a variety of verb patterns can be combined to represent the meaning intended by speakers. For example, it seems to be logical enough to use a modal in the if-clause, despite the fact that the modal occurrences as such deviate from the norm. The modals like will, can, would, and could, as we have seen from the data presented, can in actuality be employed in if-clauses. The appearance of modals in if-clauses, as revealed in (45), (50), (52), and (54), repeated here as (60)-(63) for convenience, confirm the acceptability of modal use in if-clauses, which apparently go against the textbook rules, based on the classic typology. This also provides support for the previous corpus-based studies that discovered modal uses in this fashion (e.g. Farr \& McCarthy, 2002; Gabrielatos, 2006, 2013).

(60) ...they would find the money to pay if they could be guaranteed no further litigation.

(61) If he can do it, I can do it.

(62) ...there is a third of the vote out there that is easily his to get if he could pull that vote.

(63) If he won't tell the truth, I was going to tell the truth.

As regards (60)-(63), the modals are used to express different meanings, based on what the speaker really intends to convey to the listener. In (60), the use of could may describe an unlikely situation or improbability, similar to usage of Type II. Can in the if-clause of (61) expresses an ability of the subject pronoun he, while could in (62) is expected to show possibility. In (63), the use of won't probably expresses unwillingness or refusal (Foley \& Hall, 2003).

\section{Was in TYPE II Conditionals}

Although it appears to be a rule that were, no matter what the subject is, is the preferable and correct form of be in the if-clause of Type II (Azar, 2003), the present study evidenced the preponderance of was (18 tokens) over were (12 tokens) in the second conditional. That the prescriptive grammar rule is violated here shows a tendency for native speakers of American English nowadays not to strictly conform to the if-conditional convention 
(O’Keeffe, McCarthy \& Carter, 2007).

(64) I think if there was a misunderstanding, lets' get beyond the misunderstanding.

In (64), was rather than were is used perhaps because the speaker wanted to show an agreement of the verb with the singular subject a misunderstanding, meanwhile simplifying the irrational, prescriptive rule governing Type-II conditional. Not merely is was common in the second conditional used by American English speakers, but this is also the case in British English. That is, Novogradec (2009) revealed that corpus-based data, primarily based on TV scripts of the series Friends, together with by a corpus from the British National Corpus (BNC), exhibited more uses of was than were in Type II. It should also, however, be noted here that the current-study data as well as most of Novogradec's stemmed from spoken English, e.g. TV series. The occurrences of was in this context might not be generalizable to written English, where people usually have more time and opportunity to monitor the language being used, thereby possibly producing more tokens of were, if this is considered more preferable or appropriate.

\subsubsection{Dominant Features of Spoken If-conditionals}

According to the data, one of the most important things worth discussing pertains to certain outstanding features of spoken English. First of all, gonna used as a short, spoken, and informal form of going to was found, as can be seen in (65).

(65) If you discriminate, I'm gonna fire you.

Second, a wide use of contractions in the verb forms within main clauses and if-clauses is particularly noticeable throughout the corpus-informed data. This is regarded as a dominant feature of spoken and informal English (Swan, 2005). For instance, in (66), aren't and 're are reduced forms of are not and are respectively. Likewise, don't in (67) and 'd in (68) are contractions of do not and had in that order. As for (69), the full form of can't is cannot.

(66)... if they aren't getting that, somehow they're missing out.

(67) If we don't make, I have to make a decision by Friday.

(68) If you' $d$ seen those drawings, you would have advised him...

(69) If you can't be neutral, then step aside.

The next feature indicated by the corpus centers around false starts, which arise when speakers start to say something but then change their mind and do not finish the initial utterance, ending up supplying something else instead. Such a phenomenon evidently belongs to spoken language, where speakers can spontaneously rephrase or reformulate some part of what has been said by giving a new message they prefer. In (70), for instance, the speaker began the if-clause with a false start if you are and then changed this to if you had an illness in your family. In (71), there appeared a pause after the initial part of the if-clause, i.e. if we, was uttered, and then the whole clause was supplied with a repetition of if we. In (72), two possibilities are available. First, the speaker might originally have produced the auxiliary be before changing their mind to use the verb begin instead. The other is concerned with an attempt to use the verb begin but the speaker paused after the first syllable had been uttered and then said the whole word begin.

(70) George, what would happen if you're, if you had an illness in your family.

(71) If we, if we talk about the economy, then we lose this race.

(72) If you would just explain, maybe people would be begin to understand.

The fourth spoken feature worth noticing concerns ellipses, or the omission from a clause of one or more words that would otherwise be required by the remaining elements (Renkema, 2004). From the data, ellipses often occur to a verb phrase either in an if-clause or a main clause. The clear examples of elliptical constructions are provided in (73)-(76). In particular, the omitted elements in (73) and (74) are boo, as a part of the whole verb phrase will boo, and change, as a part of choose to change respectively. In (75), only the modal have to is left since the deleted information drag you to reform is understood. The modal will in (76), likewise, is a reduced form of will hate her. It seems that ellipsis is used to avoid redundancy in language as far as the omitted element is understood and retrievable and the meaning of the entire clause is clear enough.

(73) Get ready to boo if you will.

(74) ...prisons should be a place where an individual has the opportunity to change if

they choose to. 
(75) They will drag you to reform if they have to.

(76) If you want me to hate her, Mommy, I will.

Another salient spoken characteristic found in the corpus is the use of fillers, i.e. words spoken in conversation to signal to the interlocutor that the speaker has paused to think and not yet finished (Paltridge, 2006). The fillers like and I mean are found in (77) and (78) respectively.

(77) You have somewhat of a feeling more here of self-sufficiency, like if you really want to do something yourself, you can do ...

(78) It was and I mean if he didn't say I'd leave, chances are probably the Olympic committee...

The last feature of spoken language in relation to English conditionals existing in the linguistic data is ungrammatical English use. As the data were derived from spoken, informal language, it was not uncommon to witness certain phenomena which are incomplete or do not conform to standard English. For instance, some speakers produced better, as in (79), a supposedly short form of had better. In fast or casual speech, the modal had better is usually reduced to 'd better. It is also likely that some speakers may sometimes omit'd in spontaneous speech production.

Moreover, ungrammaticality can also be seen in (80), where the verb don't does not agree in number with the singular subject $H e$. In addition, an ungrammatical structure also arises when the main-clause subject is missing, as in (81), where represents the position where there needs to be a subject.

(79) If you want to go back to that man's company, you better get it.

(80) He don't care if he dies.

(81) If the president doesn't do well, is going to drag the ticket down.

\section{Conclusion}

The findings of the present research study found support for several past relevant studies (e.g. Farr \& McCarthy, 2002; Gabrielatos, 2006, 2013; Novogradec, 2009) in that there exist a lot more patterns of if-conditionals than what is included in most ELT coursebooks. In other words, in addition to the three conventional types of if-patterns, a variety of alternative constructions are actually present in the corpus of American English like COCA. An awareness of the inadequacy, thus, of the if-conditional information contained in many textbooks, as opposed to what is used in reality, has to be raised among EFL/ESL learners or even teachers. Furthermore, the prescriptive rule prohibiting was in the second conditional is challenged by the corpus-based data, as it is clearly seen that was rather than were was more preferable for native speakers of American English. Available from the data was dominant features of spoken English, such as the use of gonna, contractions, false starts, ellipses, fillers, and non-standard forms.

It is evident that corpus-informed data are really useful since they enable learners, teachers, and English users to have easy and direct access to authentic, naturally-occurring language production, which might not be obtained from textbook or even native speakers' intuition (O'keeffe, McCarthy \& Carter, 2007). Without language corpora, EFL/ESL-related people are possibly less exposed to real use of English grammar (Reppen, 2010), e.g. if-conditionals. It should follow that they are still primarily dependent upon the classic typology of if-conditionals as suggested in a number of coursebooks and are therefore unaware of the various alternative if-constructions, which prove very common in everyday English. It is likely that confusion will face them when they come across such conditional patterns with which they are unfamiliar just because they are not introduced in any coursebooks.

\section{Pedagogical Implications}

Now that the research findings have clearly pinpointed the shortcomings of the traditional instruction of conditionals, which concentrate on only three if-conditional classic patterns, ELT teachers should consider basing their material preparation on authentic language use, e.g. corpus data (Cheng, 2012), from which they can obtain various alternative if-constructions, along with the classic main types, to be included in their lesson. Additionally, when introducing the usage of the second conditional, i.e. the present unreal condition, teachers are expected not to excessively strictly follow the prescriptive grammar rule promoting the sole use of were at the expense of was. This is because was, as the corpus-based information reveals, has actually become increasingly popular among native speakers, which are apparently detached from the arbitrary traditional were-only rule.

It may be a good idea for basic EFL/ESL learners to be familiarized first with the three customary if-conditionals available in ELT coursebooks in general. After they are able to master these classic constructions, teachers 
should also introduce the zero conditional, which is found to occur with very high frequency, as confirmed by many corpus studies (e.g. Farr \& McCarthy, 2002; O'keeffe, McCarthy, \& Carter, 2007), followed by the structure involving an imperative since this also proves to be common in real English, as shown in the present-study results. For the subsequent lessons, some other frequent extraordinary if-constructions, but not all of them, can be presented to students in the hope that this will raise their awareness of a.) the existence of alternative if-conditional patterns in real English and b.) the fact that if-conditionals in authentic use are not dominated by the classic typology, which are particularly focused on in most textbooks. Nonetheless, teachers are advised to ensure that they will not present too many different if-structures to the learners, otherwise they can become confused over the various patterns as well as complicated uses. That is, possible conditional forms that are uncommon or infrequent should be removed from the lessons. Although corpus-based materials are useful and recommended, teachers should carefully prepare their own corpus-based materials with concordance lines carefully selected from reliable native-speaker corpora. The genuine corpus data that are often used by corpus researchers needs to be avoided since the data may contain some ungrammatical, deviant uses, as previously discussed, or some technical vocabulary if they are drawn from specific fields of study. Teachers may feel free to simplify the concordance lines to highlight only the if-patterns rather than something else that could possibly turn out to be perplexing rather than learning-supportive.

\section{References}

Azar, B. (2003). Understanding and using English grammar. New Jersey: Prentice Hall.

Carter, R., \& McCarthy, M. (2006). Cambridge grammar of English. A comprehensive guide. Spoken and written English. Grammar and usage. Cambridge: Cambridge University Press.

Celce-Murcia, M., \& Larsen-Freeman, D. (1999). The grammar book: An ESL/EFL teacher's course, second edition. Singapore: Heinle \& Heinle Publishers.

Cheng, W. (2012). Exploring corpus linguistics. Language in action. London: Routledge.

Farr, F., \& McCarthy, M. J. (2002). Expressing hypothetical meaning in context: theory versus practice in spoken interaction. Paper read at The Teaching and Language Corpora (TALC) Annual Conference. Bertinoro, Italy, July $27^{\text {th }}-30^{\text {th }}, 2002$.

Ferguson, G. (2000). If you pop over there: A corpus-based study of conditionals in medical discourse. English for Specific Purposes, 20, 61-82. http://dx.doi.org/10.1016/S0889-4906(99)00027-7

Foley, M., \& Hall, D. (2003). Advanced learners' grammar. Harlow: Pearson Education Limited.

Gabrielatos, C. (2006). Corpus-based evaluation of pedagogical materials: If-conditionals in ELT coursebooks and the BNC. Paper presented. The $7^{\text {th }}$ Teaching and Language Corpora Conference. University Paris 7 Denis Diderot, 1-4 July 2006. http://eprints.lancs.ac.uk/id/eprint/882

Gabrielatos, C. (2013). If-conditionals in ICLE and the BNC: A success story for teaching or learning? In S. Granger, G. Gilquin, \& F. Meunier, (Eds.), Twenty Years of Learner Corpus Research: Looking back, moving ahead (pp. 1-15). Louvain la Neuve, Belgium: Presses Universitares de Louvain. http://www.uclouvain.be /445428.html

Lindquist, H. (2006). Corpus linguistics and the description of English. Edinburgh: Edinburgh University Press.

Novogradec, M. (2009). A corpus-based study of if-conditional forms if I was-were....as presented in pedagogical materials. As You Write It: Issues in Literature, Language, and Translation in the Context of Europe in the $21^{\text {st }}$ Century II, 6(1-2), 63-78.

O'keeffe, A., McCarthy, M., \& Carter, R. (2007). From corpus to classroom: Language use and language teaching. Cambridge: Cambridge University Press. http://dx.doi.org/10.1017/CBO9780511497650.014

Paltridge, B. (2006). Discourse analysis: An introduction. London, New York: Continuum.

Reppen, R. (2010). Using corpora in the language classroom. Cambridge: Cambridge University Press.

Renkema, J. (2004). Introduction to discourse studies. Philadelphia: John Benjamins.

Swan, M. (2005). Practical English usage. Oxford: Oxford University Press.

Thomson, A. J., \& Martinet, A. V. (1986). A practical English grammar. Oxford: Oxford University Press.

Werth, P. (1997). Conditionality as cognitive distance. In A. Athanasiadou, \& R. Dirven (Eds.), On conditionals again (pp. 243-272). Amsterdam: John Benjamins. 


\section{Copyrights}

Copyright for this article is retained by the author(s), with first publication rights granted to the journal.

This is an open-access article distributed under the terms and conditions of the Creative Commons Attribution license (http://creativecommons.org/licenses/by/3.0/). 